\title{
The association of retinitis pigmentosa with preretinal macular gliosis
}

\author{
RICHARD I. HANSEN, ALAN H. FRIEDMAN, SAMUEL GARTNER, AND \\ PAUL HENKIND \\ From the Department of Ophthalmology, Albert Einstein College of Medicine/Montefiore Hospital and \\ Medical Center, Bronx, New York
}

SUMMARY A retrospective study of the histopathological features of retinitis pigmentosa was undertaken. A consistent finding in 10 out of 10 eyes from 6 patients with retinitis pigmentosa was the presence of a preretinal membrane. The frequency of this finding has not been noted previously. Preretinal gliosis may well be responsible for the production of the abnormal glinting fundus reflex seen at the posterior pole in retinitis pigmentosa.

The presence of a clinically visible glinting reflex on the retina of patients with advanced retinitis pigmentosa similar to those appearing in patients with idiopathic preretinal gliosis led us to undertake a retrospective histopathological study of eyes with late retinitis pigmentosa. An effort was made to determine whether or not a preretinal membrane was present.

Preretinal gliosis has been reported in a number of different conditions (Wise, 1975). A study of 10 eyes obtained at necropsy from 6 patients with advanced retinitis pigmentosa revealed preretinal gliosis (fibrosis) in all of them. There have been reports of the occasional finding of such a membrane by others, but this has not been previously established as a regular feature of this disease.

\section{Methods}

Ten post-mortem eyes from 6 patients with retinitis pigmentosa were selected for study. The age, sex, pertinent medical findings, and cause of death are summarised in Table 1 . The more commonly described histopathological features of retinitis pigmentosa were present: pigment cell hyperplasia and migration to the inner retina, degeneration and loss of rods and cones and the thinning of the outer retina, hyalinisation of the arteriolar and venular walls with migration of pigment, intraretinal gliosis, loss of ganglion cell, and bipolar cell loss.

Address for reprints: Dr Richard I. Hansen, Department of Ophthalmology, Montefiore Hospital and Medical Center, 111 East 210 Street, Bronx, New York 10467

\section{Results}

Light-microscopic sections consistently revealed a preretinal membrane on the internal limiting lamina of all patients with late retinitis pigmentosa (Figs. 1 to 3 ). The membranes were invariably composed of cells with flattened ovoid nuclei and elongated cytoplasmic processes. The membranes were usually 1 cell layer thick, though some areas displayed multiple layers of cells. Wet tissue was not available for study. However, 1 celloidin block was processed for electron-microscopic study. Photomicrographs showed a cellular membrane on the internal limiting lamina which was characterised by filamentary structures and was devoid of melanin granules (Fig. 4).

Table 1 The age, sex, family history, ocular history, and cause of death of 6 patients with late retinitis pigmentosa

\begin{tabular}{|c|c|c|c|}
\hline Age & Sex & Family history/ocular history & Cause of death \\
\hline 54 & $\mathbf{F}$ & $\begin{array}{l}\text { Father, brother, and sister: } \\
\text { Retinitis pigmentosa }\end{array}$ & Carcinoma of breast \\
\hline 47 & $\mathbf{M}$ & Cataracts & $\begin{array}{r}\text { Carcinoma of rectum, } \\
\text { tuberculosis of lung }\end{array}$ \\
\hline 62 & $\mathbf{M}$ & $\begin{array}{l}\text { Poor vision since age } 8 \text { years } \\
\text { old }\end{array}$ & Carcinoma of lung \\
\hline 65 & $\mathbf{M}$ & & $\begin{array}{c}\text { Carcinoma of tongue, } \\
\text { chronic alcoholism }\end{array}$ \\
\hline 40 & $\mathbf{M}$ & 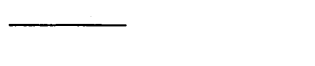 & $\begin{array}{r}\text { Glioblastoma } \\
\text { multiforme }\end{array}$ \\
\hline 47 & $\mathbf{M}$ & $\begin{array}{l}\text { Mother and } 4 \text { sibs had } \\
\text { retinitis pigmentosa; s/p } \\
\text { cataract extraction os; } \\
\text { drusen of optic nerve }\end{array}$ & Carcinoma of colon \\
\hline
\end{tabular}




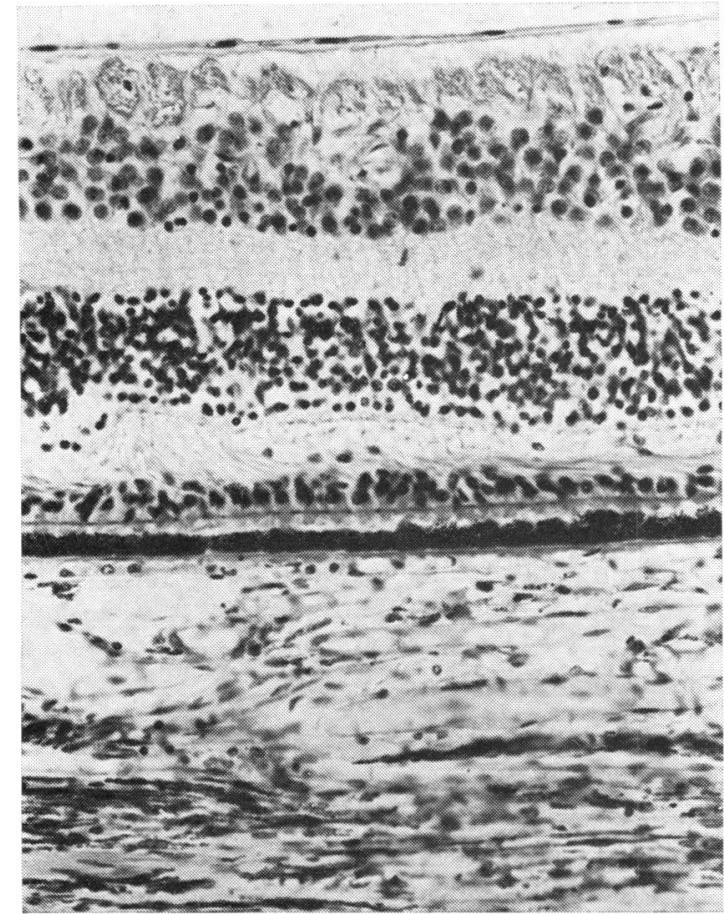

Fig. 1129520 OD. Retina of a patient with retinitis pigmentosa shows pigment cell migration and a thin, delicate membrane overlying the internal limiting membrane $(H$ and $E . \quad \times 38)$

\section{Discussion}

There have been sporadic reports of membrane structures on the internal limiting membrane (lamina) in eyes with retinitis pigmentosa (Gonin, 1902, 1903; Verhoeff, 1931; Cogan, 1950; Wolter, 1957; and Eichholtz, 1974).

Verhoeff (1931) described a case of retinitis pigmentosa with tuberculosis of the iris in which he found a neuroglial membrane on the inner surface of the retina. This membrane was 3 or 4 cells thick, and nowhere was it seen communicating with the neuroglia within the retina. Verhoeff also noted a delicate neuroglial membrane over the surface of the disc. Cogan (1950), in an extensive histologic study of 5 cases of retinitis pigmentosa $(2$ post mortem, 2 enculeated for glaucoma, 1 enucleated for anterior uveitis), observed that the inner layers of the retina occasionally showed a glial membrane extending into the vitreous. Wolter (1957), using the special glial staining method of del Rio Hortega, described 1 case of retinitis pigmentosa in a 75year-old man who had died in dementia. The patient had been followed up clinically for many years before his death. Wolter concluded that the cause of the waxy pallor of the disc observed clinically was due to a combination of a new formed layer of astrocytes on the inner surface of the papilla, of nerve fibre degeneration, and of the scar formation of glia and connective tissue within the optic nerve

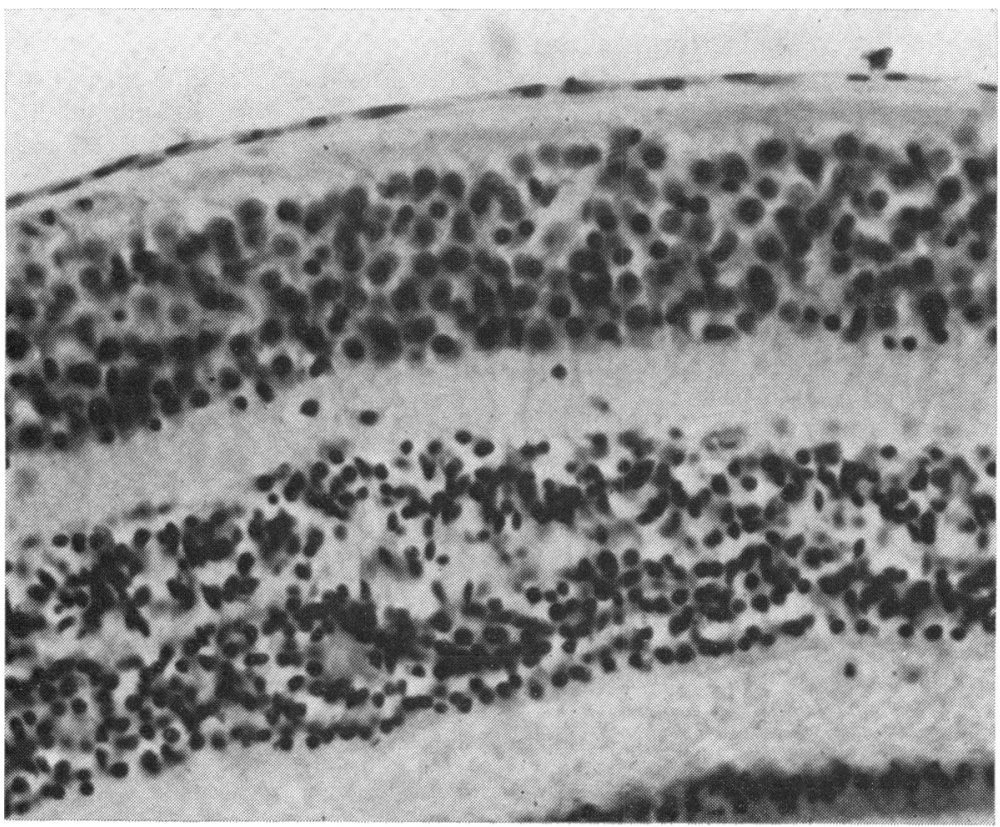

Fig. 2129520 OD. Another section of same eye as Fig. 1 showing preretinal membrane $(H$ and $E . \quad \times 54)$ 


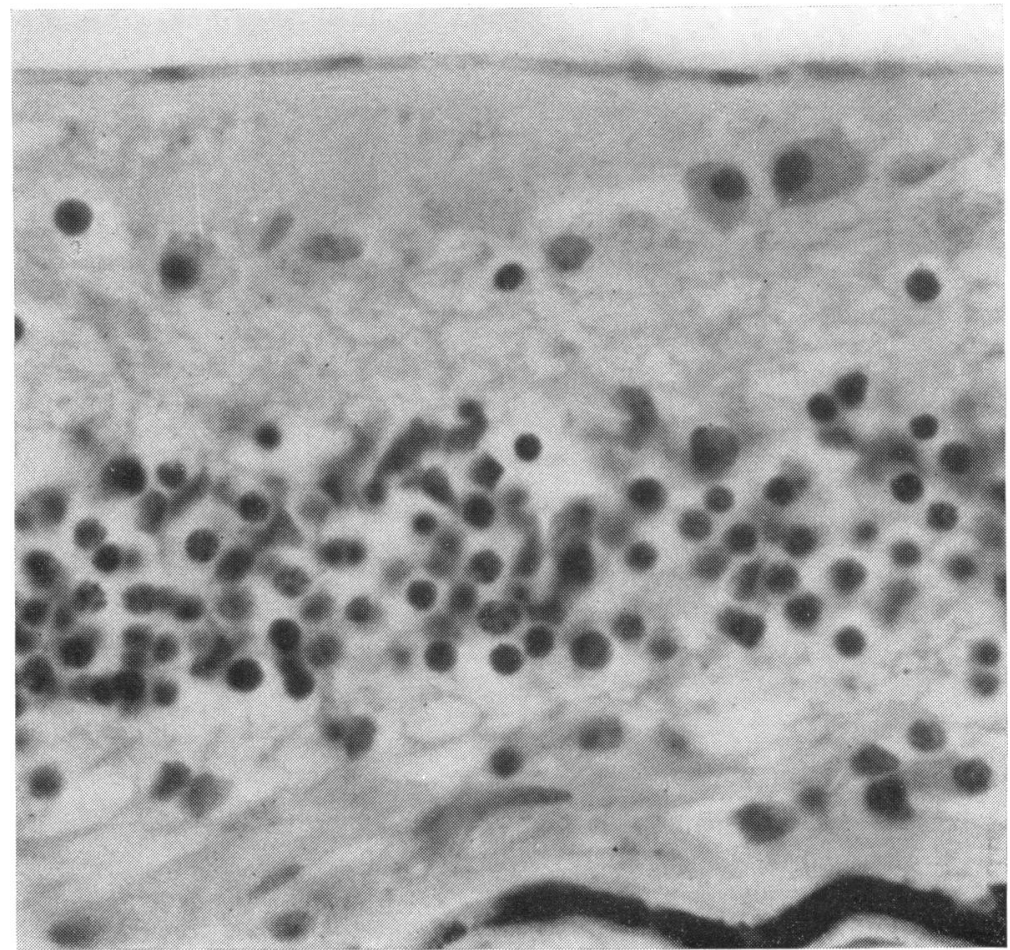

Fig. 3 18874002. Section of retina showing thin continuous preretinal membrane $(H$ and $E$. $\times 137)$

head. Wolter also noted that on the inside of the internal limiting membrane of the retina a new layer of peculiar flat cells with long intertwined processes had developed.

Wise (1975) had classified preretinal membranes according to aetiology (see Table 2).
Roth and Foos (1971) described surface wrinkling retinopathy (macular pucker) in a study of 1000 post-mortem eyes. An epiretinal membrane was present in $3.5 \%$ of the specimens described and consisted of 1 or more layers of flattened cells, which usually bridged across the crests of the wrinkles.

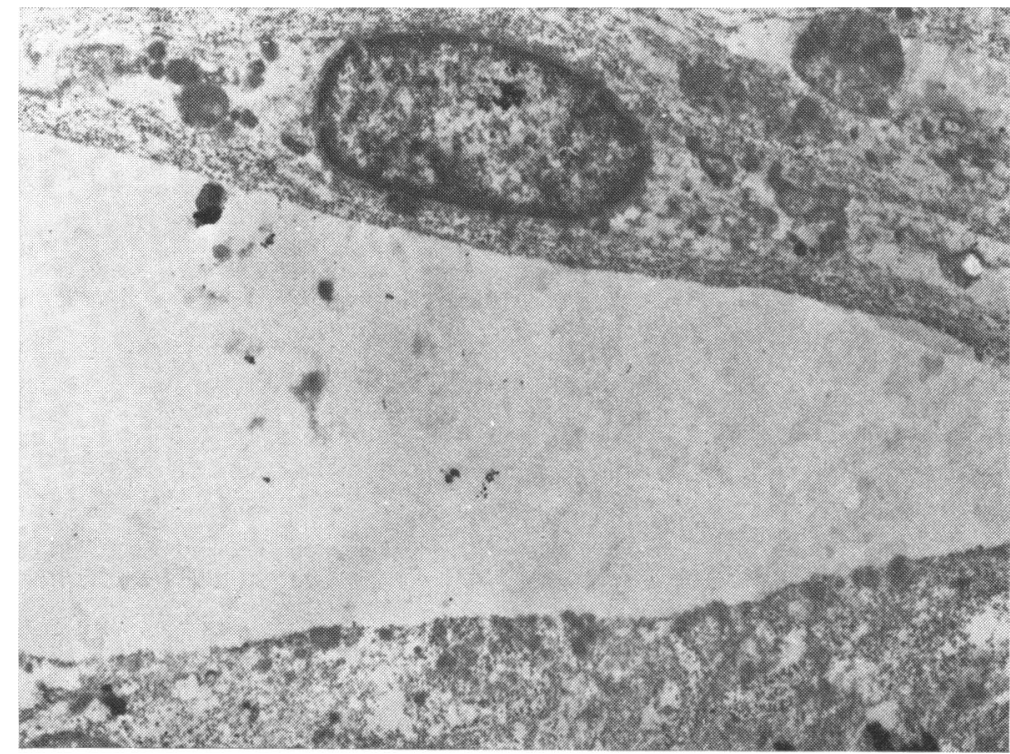

Fig. 4 Electron-micrograph of preretinal membrane shows prominent nucleus, rough surfaced endoplasmic reticula, numerous fine cytoplasmic microfilaments, and collagen strands. $\times 10900$ 
Table 2 Classification of preretinal membranes, adapted from Wise (1975)

1. Idiopathic preretinal macular gliosis

2. Occurring after vascular occlusions

3. Occurring after photocoagulation

4. Congenital

5. Macular pucker after retinal detachment surgery

6. Associated with previous trauma

7. Secondary to inflammation

8. Proliferative reaction after vein obstruction

9. Occurring after cataract extraction

Roth and Foos (1971) concluded that these cells were retinal in origin and arose from focal defects in the inner limiting lamina.

Eichholtz (1974) discussed 2 cases of retinitis pigmentosa, the second of which had had photocoagulation for cystoid macular oedema and then was subsequently found to have a malignant melanoma. Histopathological study showed a preretinal membrane. The author commented that the preretinal membrane may have been associated with the photocoagulation.

Bellhorn et al. (1975) described 2 cases of idiopathic preretinal macular gliosis in which a clinically glinting retinal reflex had preceded the development of retinal folds and retinal traction lines. Histopathological study in both cases showed a break in the inner limiting lamina through which glial cells had migrated and had proliferated on the retinal surface. There were no vitreoretinal adhesions. The ultrastructural similarities of these lesions to the preretinal glial membranes seen in other disease entities suggested to the authors the possibility of a common aetiology.

Laqua and Machemer (1975) and Machemer and Laqua (1975) experimentally produced retinal detachments in owl monkeys and noted massive preretinal traction. Cells of retinal origin formed a preretinal membrane and were heavily interdigitated by long cytoplasmic processes. Zonulae occludentes were present, and the cytoplasm often contained bundles of filaments arranged in a parallel fashion. Pigment granules were occasionally seen. It was observed with DNA studies that these cells were astrocytes and that they had grown out of the retina through focal interruptions in the inner limiting lamina and had proliferated.

Kenyon et al. (1975), in describing the preretinal membrane seen in pars planitis, observed elongated fibrocytic-appearing cells with thin processes interposed among collagenous aggregates. Roughsurfaced endoplasmic reticula were present, and the authors concluded that these cells resembled fibrous astrocytes.

Clarkson et al. (1977) have recently reviewed 2000 eye pathology cases (388 surgical, 1612 post mortem) to determine the prevalence of preretinal membranes.
The prevalence of preretinal membranes in surgical cases was $21.5 \%$, while in post-mortem eyes it was $1.7 \%$. A total of 168 cases of previously diagnosed preretinal membranes was also reviewed. Retinitis pigmentosa was not among those cases presented.

We conclude that the glinting retinal reflex of the fundus often described in retinitis pigmentosa is caused by preretinal glial membranes. Ten out of 10 eyes with late retinitis pigmentosa in patients who had never had eye surgery or photocoagulation and who had died of unrelated causes had a preretinal membrane. Electron-microscopic study showed that this membrane was composed of fibrous astrocytes. It is possible that the preretinal membrane which is so consistently present in our cases of late retinitis pigmentosa shares a common aetiology with the preretinal membranes classified by Wise (1975).

This work was supported in part by Grant RO1EY-00613-06 of the National Eye Institute of the National Institute of Health, Washington, DC, USA.

\section{References}

Bellhorn, M. B., Friedman, A. H., Wise, G. N., and Henkind, P. (1975). Ultrastructure and clinicopathologic correlation of idiopathic preretinal macular fibrosis. American Journal of Ophthalmology, 79, 366.

Clarkson, J. G., Green, W. R., and Massof, D. (1977). A histopathologic review of 168 cases of preretinal membrane. American Journal of Ophthalmology, in press.

Cogan, D. G. (1950). Symposium: primary chorioretinal aberrations with night blindness: pathology. Transactions of the American Academy of Ophthalmology and Otolaryngology, 54, 629.

Eichholtz, W. (1974). Histologie der retinopathia pigmentosa cum et sine pigmento. Klinische Monatsblatter für Augenheilkunde, 164, 467.

Gonin, J. (1902, 1903). Examen anatomique d'un oeil atteint de retinopathie pigmentaire en voie d'evolution avec scotome zonulaire. Annales Oculiste (Paris), 128, 401; 129, 24.

Kenyon, K. R., Pederson, J. E., Green, W. R., and Maumenee, A. E. (1975). Fibroglial proliferation in pars planitis. Transactions of the Ophthalmological Societies of the United Kingdom, 95, 391.

Laqua, H., and Machemer, R. (1975). Glial cell proliferation in retinal detachment (massive periretinal proliferation). American Journal of Ophthalmology, 80, 602.

Machemer, R., and Laqua, H. (1975). Pigment epithelial proliferation in retinal detachment (massive periretinal proliferation). American Journal of Ophthalmology, 80, 1.

Roth, A. M., and Foos, R. Y. (1971). Surface wrinkling retinopathy in eyes enucleated at autopsy. Transactions of the American Academy of Ophthalmology and Otolaryngology, 75, 1047.

Verhoeff, F. H. (1931). Microscopic observation in a case of retinitis pigmentosa. Archives of Ophthalmology, 5, 392.

Wise, G. N. (1975). Clinical features of idiopathic pre-retinal macular fibrosis. American Journal of Ophthalmology, 79, 349.

Wolter, J. R. (1957). Retinitis pigmentosa: a histologic study with a new technique. Archives of Ophthalmology, 57, 539. 